\title{
\begin{tabular}{l|l} 
Mibraries & DSpace@MIT
\end{tabular}
}

\author{
MIT Open Access Articles
}

\section{Investigations of Aluminum-Doped Self-Healing Zircaloy Surfaces in Context of Accident-Tolerant Fuel Cladding Research}

The MIT Faculty has made this article openly available. Please share how this access benefits you. Your story matters.

Citation: Carr, James, Gokul Vasudevamurthy, Lance Snead, Brian Hinderliter, and Caleb Massey. "Investigations of Aluminum-Doped Self-Healing Zircaloy Surfaces in Context of Accident-Tolerant Fuel Cladding Research." Journal of Materials Engineering and Performance 25, no. 6 (May 5, 2016): 2347-2355.

As Published: http://dx.doi.org/10.1007/s11665-016-2094-4

Publisher: Springer US

Persistent URL: http://hdl.handle.net/1721.1/105854

Version: Author's final manuscript: final author's manuscript post peer review, without publisher's formatting or copy editing

Terms of Use: Article is made available in accordance with the publisher's policy and may be subject to US copyright law. Please refer to the publisher's site for terms of use. 


\title{
Investigations of Aluminum-Doped Self-Healing Zircaloy Surfaces in Context of Accident-Tolerant Fuel Cladding Research
}

\author{
James Carr, Gokul Vasudevamurthy, Lance Snead, Brian Hinderliter, and Caleb Massey
}

(Submitted March 1, 2016; in revised form April 17, 2016; published online May 5, 2016)

\begin{abstract}
We present here some important results investigating aluminum as an effective surface dopant for increased oxidation resistance of zircaloy nuclear fuel cladding. At first, the transport behavior of aluminum into reactor grade zircaloy was studied using simple diffusion couples at temperatures greater than $770 \mathrm{~K}$. The experiments revealed the formation of tens of microns thick graded $\mathrm{Zr}$-Al layers. The activation energy of aluminum in zircaloy was found to be $\sim 175 \mathrm{~kJ} / \mathrm{mol}(\sim 1.8 \mathrm{eV})$, indicating the high mobility of aluminum in zircaloy. Subsequently, aluminum sputter-coated zircaloy coupons were heat-treated to achieve surface doping and form compositionally graded layers. These coupons were then tested in steam environments at 1073 and $1273 \mathrm{~K}$. The microstructure of the as-fabricated and steam-corroded specimens was compared to those of pure zircaloy control specimens. Analysis of data revealed that aluminum effectively competed with zircaloy for oxygen up until $1073 \mathrm{~K}$ blocking oxygen penetration, with no traces of large scale spalling, indicating mechanically stable interfaces and surfaces. At the highest steam test temperatures, aluminum was observed to segregate from the $\mathrm{Zr}$-Al alloy under layers and migrate to the surface forming discrete clusters. Although this is perceived as an extremely desirable phenomenon, in the current experiments, oxygen was observed to penetrate into the zirconium-rich under layers, which could be attributed to formation of surface defects such as cracks in the surface alumina layers.
\end{abstract}

Keywords aluminum, corrosion and wear, failure analysis, heat treatment, intermetallic, non-ferrous metals, oxidation

\section{Introduction}

Hafnium-free zirconium alloys are extensively employed in the nuclear industry as the material of choice for fuel cladding in light water reactors (LWRs) (Ref 1). These alloys have superior neutronic and thermal properties under normal operating conditions. During normal operation, the zircaloy cladding ( $\alpha$-phase) forms a zirconia layer due to interaction with water. Over a period of time, the brittle zirconia layer slowly but steadily grows in thickness. At the same time, the cladding also picks up significant quantities of hydrogen from water, which penetrates deep into the material matrix forming highly brittle zirconium-hydride (Ref 2 ). The formation of these two brittle phases, in an otherwise ductile cladding, is not considered an issue of deep concern during normal operation. However, this can potentially manifest into a major catastrophe during a loss of coolant accident (LOCA), as evident in both Fukushima and Three Mile Island (TMI) nuclear events. During a LOCA, a breach in the pressure boundary causes the reactor

James Carr, Gokul Vasudevamurthy, and Caleb Massey, Mechanical and Nuclear Engineering, Virginia Commonwealth University, Richmond, VA; Lance Snead, Nuclear Engineering, Massachusetts Institute of Technology, Cambridge, MA; and Brian Hinderliter, Mechanical and Industrial Engineering, University of Minnesota, Duluth, MN. Contact e-mail: vasudevamurthy.gokul@ gmail.com. to lose its cooling ability (Ref 3 ). In the absence of active cooling, the cladding can heat up from an operating temperature of $\sim 625 \mathrm{~K}$ to temperatures well beyond $1273 \mathrm{~K}$ (Ref 4) in a short duration. In most LOCA scenarios, an intact emergency core cooling system (ECCS) typically activates a few minutes into the event. The ECCS dumps cold water into the core thus temporarily restoring active cooling. However, if the cladding temperature exceeds $1073 \mathrm{~K}$ following a partial uncovering scenario (Ref 2), attempts to cool the core will result in production of large quantities of hydrogen due to the interaction of zircaloy with steam (Ref 2). This release of hydrogen is even more concerning when the ECCS is delayed in activating or fails to operate completely. This sudden cooling process often leads to spalling of the brittle oxide layer, on account of thermal shock, resulting in the exposure of underlying zirconium layer along with the interspersed brittle hydride phases. This phenomenon leads to large scale runaway oxidation and the production of significant amounts of hydrogen precipitating a possible explosive situation.

In order to prevent these potentially catastrophic scenarios, research is currently underway to develop cladding materials with enhanced corrosion resistance. One of the topics presently under active consideration is the modification of zircaloy's surface with much more potent metallic or non-metallic element(s), which would perform three primary functions without compromising the essential functions of the zircaloy cladding: (1) reduce the amount of zircaloy on the surface; (2) form either a superior or comparable oxide layer offering increased protection to the underlying pure zirconium layers in addition to providing a larger barrier for hydrogen diffusion, therefore reducing the hydride content; and (3) act as a sacrificial layer that will be the first to spall in thermal shock scenarios, thus delaying the degradation of the underlying zirconium layer. 
Several materials such as aluminum, silicon, and chromium are currently being investigated as candidate materials for zircaloy surface modification (Ref 5, 6). Additionally, a new advanced class of materials such as silicon carbide ( $\mathrm{SiC})$ and iron, chromium, and aluminum (FeCrAl) alloys are being proposed to totally replace zircaloy. While the developments of such advanced alloys are expected to take time, the experiments described here were in context of evaluating much more simplistic methods, which if successful could have minimal regulatory impacts as opposed to using an entirely new class of fuel cladding materials.

Among the various materials mentioned above, aluminum is a strong candidate for use in zircaloy modification on account of its corrosion resistance due to the formation of excellent passivation layers containing alumina (Ref 7). Aluminum also has excellent neutronic properties that are valued in a LWR environment. Incidentally, among metals, aluminum is also reported to have the least permeability to hydrogen, which is a major contributor of cladding embrittlement in water-cooled reactors (Ref 8$)$. In the past, limited studies have looked into using aluminum as an effective material to enhance the oxidation resistance of zircaloy especially for use in pressurized heavy water reactors (Ref 9). Aluminum alloys have also been traditionally employed as fuel cladding for research and test reactors (Ref 10,11) where metallic instead of ceramic fuels are used for its excellent thermal conductivity. Furthermore, aluminum has also emerged as a primary alloying material in some of the advanced alloys (example: FeCrAl) being considered as candidates to replace zircaloy cladding in LWRs.

In the present study, aluminum was chosen to modify the surface of zircaloy by introducing it as a surface dopant after careful considerations of the favorable relevant attributes discussed above. Initially, the diffusion behavior of aluminum in zircaloy and the resulting changes in composition resulting from the modification were studied using traditional diffusion couples. Subsequently, magnetron sputtering followed by heat treatment was employed to produce optimal surface modifications to achieve greater control on the amount of aluminum deposited on the surface, bearing in mind a potential for scale up. The surface-modified samples were ultimately tested to study their behavior in high-temperature steam environments mimicking conditions existing in limited LWR LOCA scenarios. The results of this developmental study are presented along with relevant discussions.

\section{Material and Methods}

As a first step, the transport behavior of aluminum in zircaloy was investigated by employing sandwich diffusion couples. Square coupons of $\left(5 \times 5 \times 0.65 \mathrm{~mm}^{3}\right)$ reactor grade zircaloy (1.52\% Sn, $0.16 \% \mathrm{Cr}, 0.23 \% \mathrm{Fe}, 0.19 \% \mathrm{Ni}, \mathrm{Zr}$ remaining) procured from ATI Wah Chang and aluminum foil (purity: 99.999\%, $0.25 \mathrm{~mm}$ thick) supplied by Sigma-Aldrich were used to assemble sandwich diffusion couples. The surfaces of both the substrate and the aluminum foil were polished to $0.25 \mu \mathrm{m}$ using diamond slurry with ultrasonic cleaning at each grinding and polishing step. The couples were heat-treated at 770, 820, 870, and $910 \mathrm{~K}$ for duration of $6 \mathrm{~h}$ in an ultrahigh purity argon tube furnace. Post processing, the couples were metallographically prepared and characterized using a Hitachi scanning electron microscope (SEM) to calculate the diffusion coefficient of aluminum in zircaloy. Electron energy dispersive spectroscopy (EDS) and X'Pert X-ray diffractometer (XRD) were used to analyze the elemental distribution and the chemical composition across the diffusion zone.

Following the diffusion experiments, new zircaloy coupons were coated with high purity aluminum thin films using an Orion-5 magnetron sputter coater. The thickness of the coatings was estimated using the initial and final mass with a Sartorius brand AC2115 microbalance (accuracy 0.0001 g). Further, the thicknesses of the films on representative as-coated specimens were verified with the scanning electron microscopy (Hitachi). The coated specimens were subsequently heat-treated in vacuum at $823 \mathrm{~K}$ for a duration of $2 \mathrm{~h}$. The temperature and time of the annealing processes were fixed based on the optimal layer thicknesses observed in the diffusion experiments. Post annealing, the specimens were metallographically prepared and characterized using the SEM. Low speed diamond saw, high hardness resin, and gentle polishing were utilized during postprocessing preparation to minimize damage to the samples. Adhesion testing was performed following ASTM D3359-09 standard using a Gardco Pa-2000 kit (Ref 12) on the coated specimens.

Finally, experiments were conducted to test the corrosion behavior of coated and heat-treated specimens along with as-received zircaloy specimens in high-temperature steam environments simulating potential LOCA conditions. The experimental setup is shown in Fig. 1. Steam was produced from an autoclave at a constant pressure of $\sim 28 \mathrm{kPa}$ and passed over samples placed in a model UP150 automatic temperaturecontrolled tube furnace consisting of a 316 stainless steel heating tube retrofitted with steam inlet and outlet valves. Prior starting the steam flow, the tube furnace was purged using ultrahigh purity argon to expel air. Steam corrosion experiments were conducted at 1073 and $1273 \mathrm{~K}$ (furnace temperature) in an unlimited steam environment for durations ranging from 1 to $2 \mathrm{~h}$. Subsequently, the microstructure and composition of the steam-corroded specimens were characterized using SEM.

\section{Results and Discussions}

\subsection{Aluminum Diffusion and Doping Experiments}

In all diffusion experiments, two layers were observed, as seen in Fig. 2. The phase contrast seen in the SEM backscatter images clearly indicates different compositions, ranging from aluminum, aluminum-zirconium alloy across the diffusion zone, to pure zircaloy. Based on the atomic percent from EDS scans and the established aluminum-zirconium phase diagram, the chemical composition of the phases was determined to consist of $\mathrm{Al}_{3} \mathrm{Zr}$ and $\mathrm{Al}_{3} \mathrm{Zr}_{2}$ (Ref 13, 14), which were subsequently confirmed by XRD analysis (Fig. 3). The formation of these compositionally graded $\mathrm{Zr}$-Al layers is expected to be extremely beneficial as opposed to a discrete coating in balancing of the significantly differing thermal expansion coefficients of aluminum and zirconium (Ref 15). In the absence of formation of such layers, it can be assumed that the probability of spalling of any discrete layers are very high both under normal and abnormal reactor conditions (scenarios leading to thermal shock).

Further, as anticipated, the phase diagram predicts that the melting point of the transitions zones is much lower than 


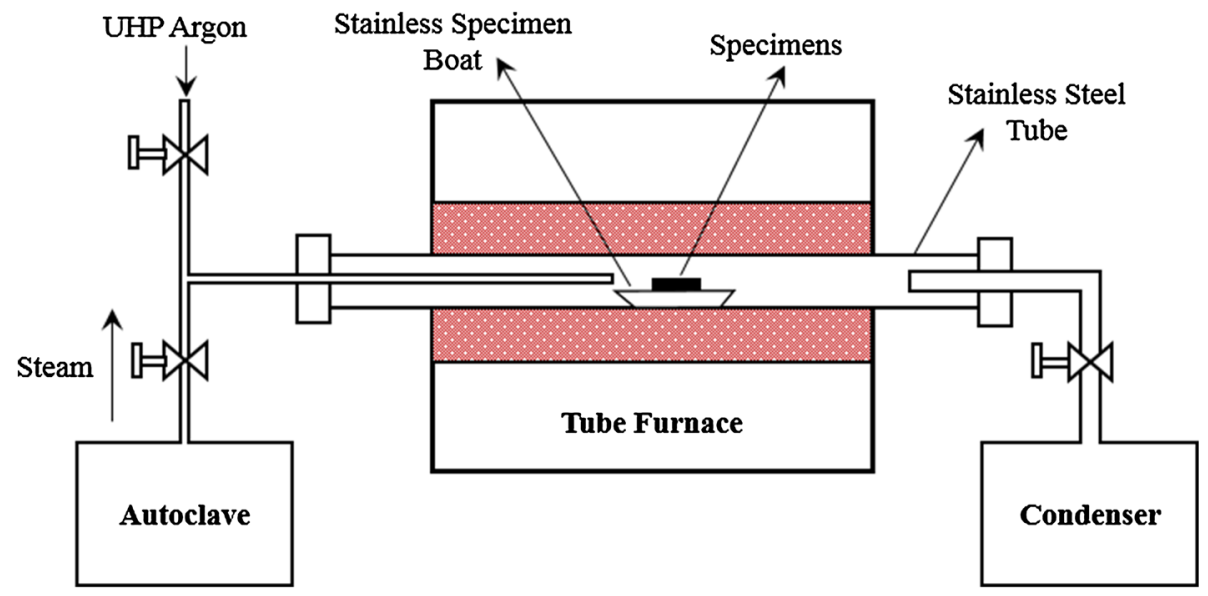

Fig. 1 High-temperature steam corrosion experiments


Fig. 2 Results of the diffusion experiments: (a) Microstructure of the diffusion zone showing two distinct layers (1 and 2); (b) EDS map of zirconium distribution; (c) EDS map of aluminum distribution; (d) EDS concentration profile of $\mathrm{Al}$ and $\mathrm{Zr}$ along the line shown in (a)

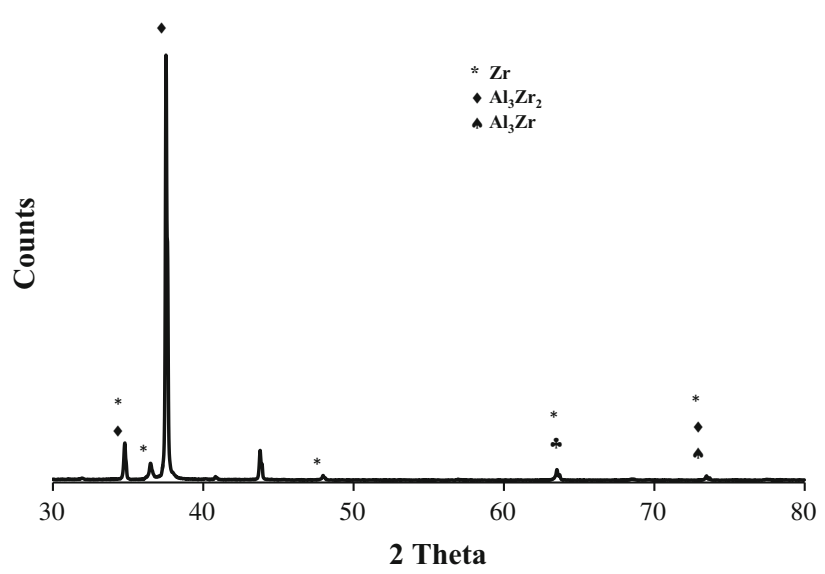

Fig. 3 X-ray diffraction results of the surface following the diffusion experiments

zirconium, but higher than aluminum (Ref 13, 14). The aspredicted melting points of the diffusion layers $\mathrm{Al}_{3} \mathrm{Zr}$ and $\mathrm{Zr}_{2} \mathrm{Al}_{3}$ are 1853 and $1863 \mathrm{~K}$, respectively. It is noteworthy that these melting points are lower than that of zircaloy; however, the values are well above the NRC specified temperature limit of $1473 \mathrm{~K}$ (Ref 16) and perhaps could be viewed as an acceptable trade-off if this surface modification indeed resulted in improved accident tolerance. Additionally, it can be argued that the melting points of these two phases are similar to stainless steels, which have been successfully used as alternative cladding materials and hence are not considered a serious issue.

Since the formation of these diffusion layers is critical for the anticipated improvement in corrosion resistance and adhesion, understanding the kinetics of aluminum diffusion in zircaloy becomes important. In this context, employing the micrographs of the cross-sections and measuring the thickness of the diffusion layers at each temperature, the activation energy $(Q)$ was calculated by plotting the natural $\log$ of $x^{2} / t$ (where $x$ is the diffusion layer thickness at a given temperature and $t$ is the time) as a function of the inverse test temperature (Fig. 4). The thickness measurements were on the range of tens to hundreds of micrometers with the standard deviation from each experiment less than 10 micrometers. The pre-exponent and the $Q$ values were estimated using the y-intercept and the slope of the curve, respectively, assuming non-steady state diffusion. The resulting values of $Q$ for the diffusion of aluminum into zircaloy were estimated to be $\sim 175 \mathrm{~kJ} / \mathrm{mol}$ $(1.8 \mathrm{eV})$ and the pre-exponent was estimated to be $0.0468 \mathrm{~m}^{2} /$ s. The values of $Q$ estimated during the current experiments agree with those reported in the literature in context of aluminum diffusion in pure zirconium. In similar diffusion 
experiments with pure zirconium, Kidson and Miller (Ref 9) and Laik et al. (Ref 17) reported activation energies of 193 and $188 \mathrm{~kJ} / \mathrm{mol}$, respectively. Further, the pre-exponential factor of $0.0468 \mathrm{~m}^{2} / \mathrm{s}$ resulting from the current analysis is also in good agreement with those reported in the literature (Ref 18). Any deviation from the values resulting in the current experiments and those reported in literature can be partly attributed to

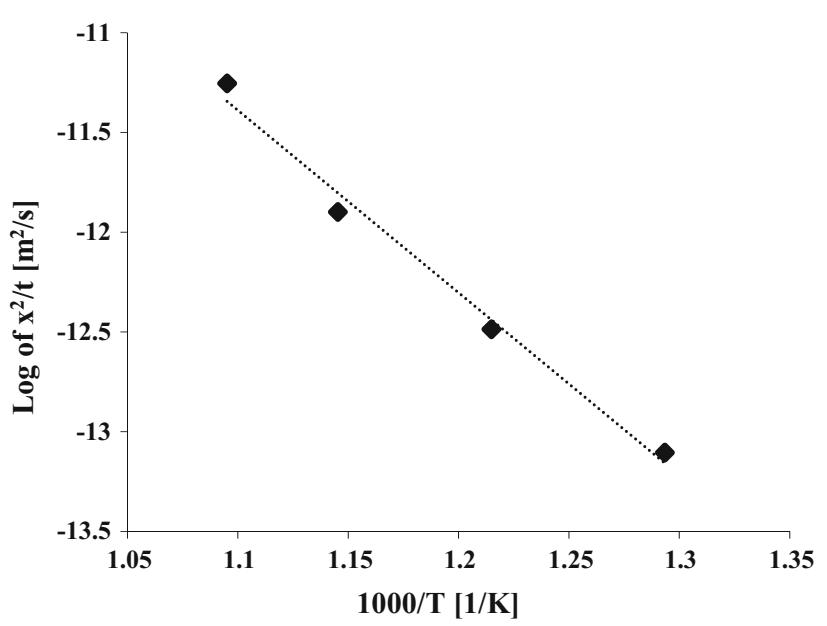

Fig. 4 Plot of the variation of the square diffusion thickness over time vs. temperature variations in experimental parameters and material pedigree (pure zirconium versus zircaloy).

Nevertheless, the low values of activation energy indicate the relative ease of aluminum transport in zircaloy. The observed ease of transport is significant as it directly relates to the ability of aluminum embedded in the zircaloy to effectively move to the surface, thus forming a renewed alumina layer. In cases where the outer most layer spall during a high-temperature event, the presence of aluminum in the under layers could result in a potentially self-healing layer. This phenomenon is expected to reduce the exposure of large quantities of the underlying virgin zircaloy to the environment. At the time of the undesirable event, the aluminum is expected to offer a tough competition to zirconium in context of oxidation.

\subsection{Results of the Coating Experiments}

Although the diffusion couple experiments were conducted in context of studying aluminum transport in zircaloy, this method would be less suitable for large-scale production on account of the complexity associated with controlling the purity of aluminum and intactness of the contact surface for aluminum diffusion. Another critical concern with such a setup is the interfacial residual stresses due to thermal expansion and lattice mismatch. To address these issues and fabricate more mechanically robust thin film interfaces, magnetron sputter coating was employed to provide a quick, standardized, and uniform diffusion source of aluminum at the surface of zircaloy.
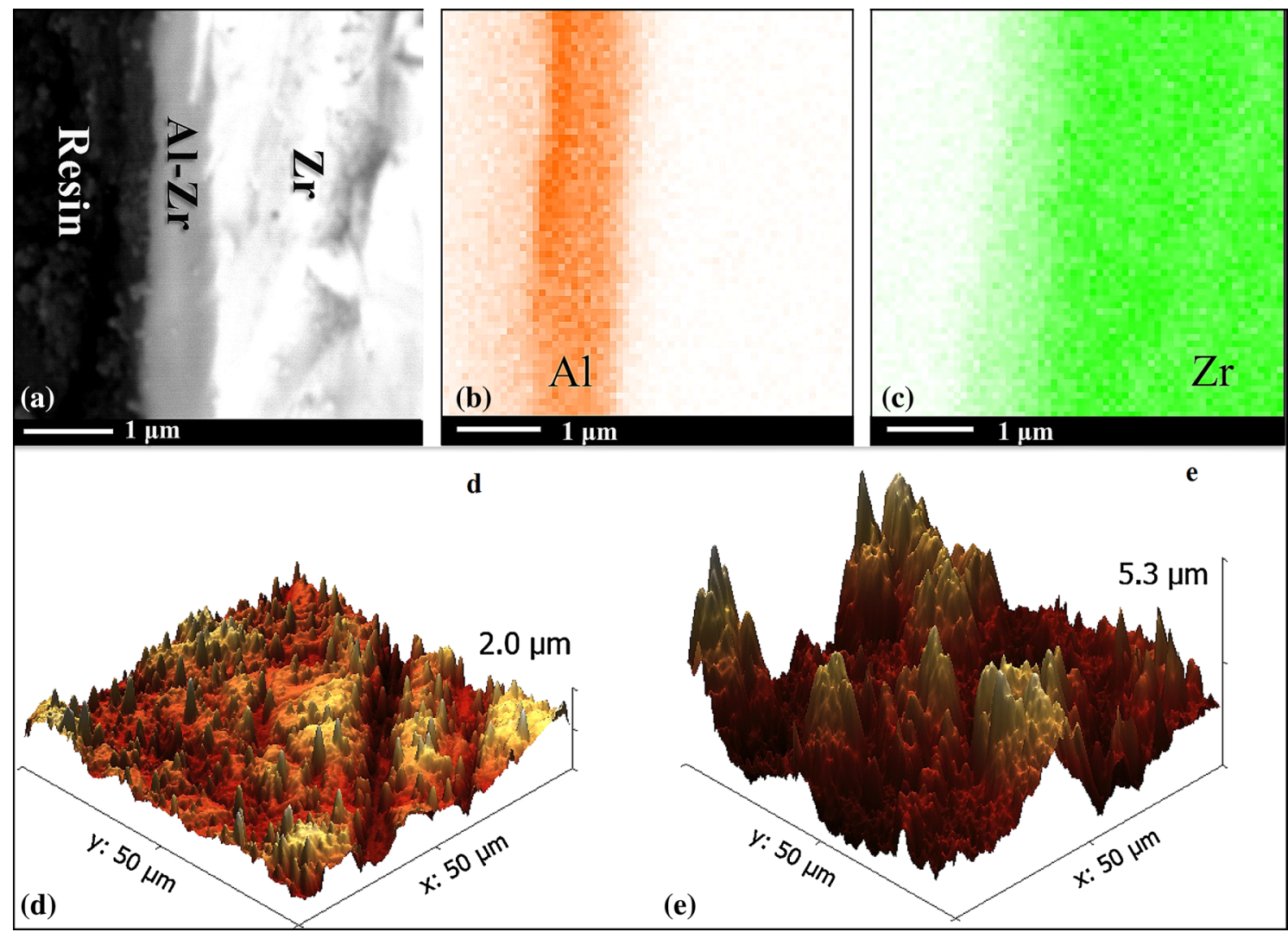

Fig. 5 (a) Microstructure of sputtered and heat-treated Al-doped zircaloy; (b) Aluminum distribution in sputtered and heat-treated specimen; (c) Zirconium distribution in sputtered and heat-treated specimen; (d) Surface topography of as-sputtered zircaloy specimen; (e) Changes in surface topography of following heat-treatment 

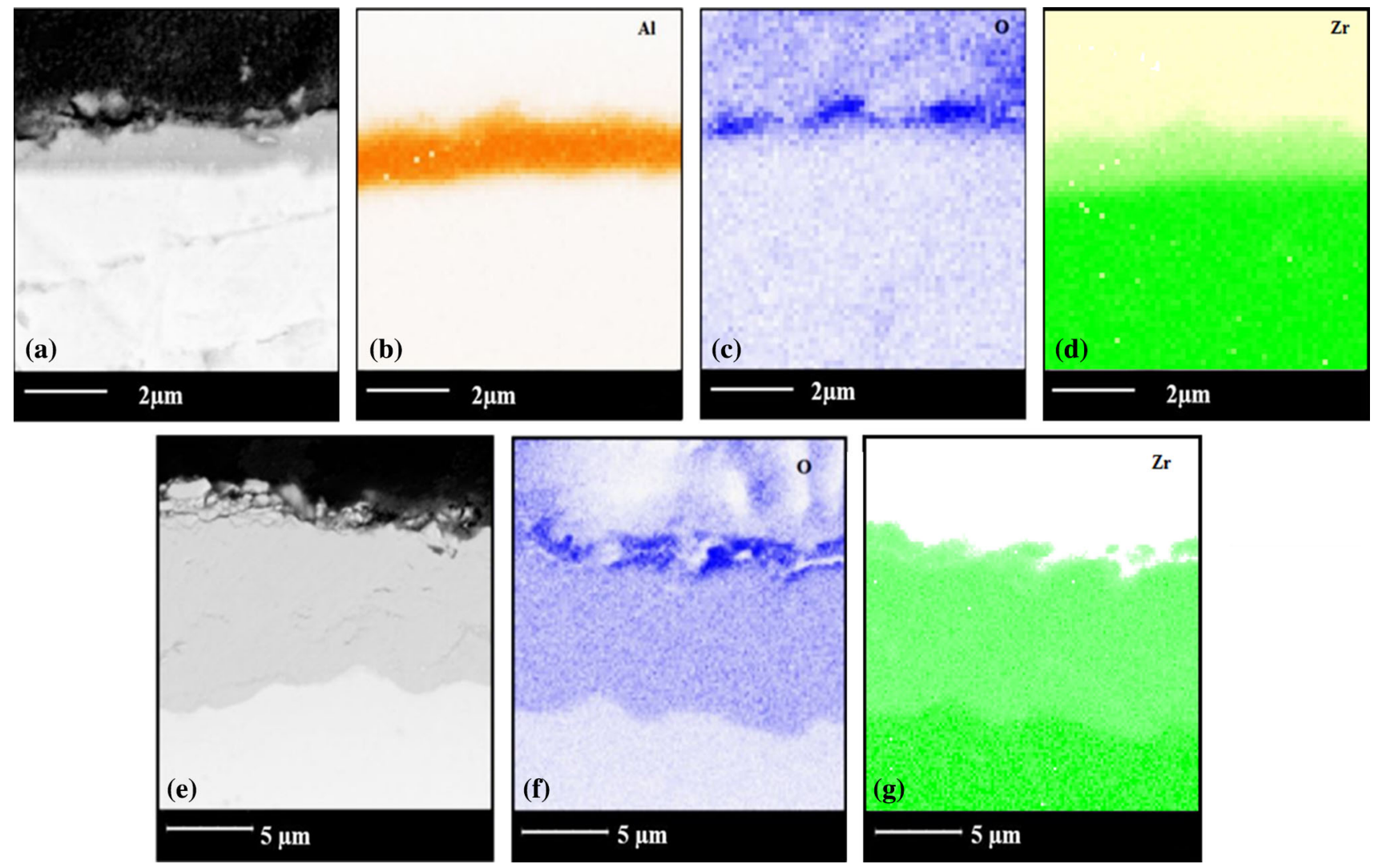

Fig. 6 Steam corrosion experiments at $1073 \mathrm{~K}$, (a) Al-doped specimen microstructure with oxide layer formation, (b) EDS mapping shows concentration of aluminum at the surface, (c) EDS mapping shows concentration of oxygen at the surface coinciding with aluminum, (d) Distribution of zirconium in al-doped samples after steam corrosion, (e) Pure zircaloy control specimen microstructure, (f) EDS mapping showing deeper penetration of oxygen into pure zircaloy, (g) Distribution of zirconium in steam-corroded control specimen

Additionally, this method is also expected to provide adequate control on the desired coating thickness. In the present work, sputtering was employed to deposit 1-2 $\mu \mathrm{m}$ thick layers of pure aluminum (Fig. 5) on zircaloy coupons over relatively short durations $(2-4 \mathrm{~h})$ followed by vacuum heat-treatment to facilitate diffusion.

Post-annealing microstructural characterization of specimens showed the formation of $\mathrm{Al}_{3} \mathrm{Zr}$ layer similar to those observed in the diffusion experiment, albeit much smaller in thickness as expected. A stark contrast from the diffusion experiments was the absence of the $\mathrm{Al}_{3} \mathrm{Zr}_{2}$ under-layer, the reason for which could only be attributed to the possible metastable nature of $\mathrm{Al}_{3} \mathrm{Zr}_{2}$ and subsequent conversion of this layer to $\mathrm{Al}_{3} \mathrm{Zr}$ reported in the literature (Ref 19). The representative microstructures along with the corresponding EDS results of the sputter coated and heat-treated specimens are shown in Fig. 5. The analysis of the heat-treated surface using AFM (Fig. 5) showed the formation of micron-sized defects in the form of minute Al-rich clusters leading to increased surface roughness after the heat-treatment process. This can be partially attributed to the heat-treatment parameters employed and perhaps to some limited oxidation of the surface layer during the process, although attributable to a far lesser extent to the later, because extreme care was taken to tightly control the heattreatment environment. Similar features such as Al-rich islands' have been reported on surface of aluminum-doped metals in the literature (Ref 20) and have often been considered an artifact associated with the deposition method. Adhesion testing performed according to ASTM (Ref 12) on the heat-treated specimens ranked at $5 \mathrm{~B}$, indicating $0 \%$ area removed from the coated surface, which further confirmed that even with the formation of surface blisters, the doped surface remained intact without any observable de-bonding.

\subsection{High-Temperature Steam Oxidation Experiments}

As described in the experimental section, Al-doped (sputtered and heat-treated) and pure zircaloy specimens were subject to high-temperature steam environment tests for a comparative investigation on the behavior of the coated specimens in simulated LOCA conditions.

In the representative samples seen in Fig. 6, at $1073 \mathrm{~K}$, the average thickness of the oxidation layers in pure zircaloy specimens was $\sim 8 \mu \mathrm{m}$ after a total of $120 \mathrm{~min}$ of steam exposure, while the average thickness measured at the higher test temperatures $1273 \mathrm{~K}$ was $\sim 20 \mu \mathrm{m}$ (Fig. 7). In comparison, average oxide layer thicknesses of $\sim 0.7$ and $\sim 22 \mu \mathrm{m}$ at 1073 and $1273 \mathrm{~K}$, respectively, were observed in the Al-doped specimens after 120 mins. It is noted here that in the latter case, the oxidation layer thickness reported included both the zirconium and aluminum oxide layer thicknesses. EDS maps of representative specimens tested at $1273 \mathrm{~K}$ (Fig. 7) showed the formation of the oxide layers and the depth of oxygen penetration in the Al-doped specimens. It is clearly seen that in these specimens, the oxygen concentrated heavily at the surface where the aluminum too is observed to peak via segregation 

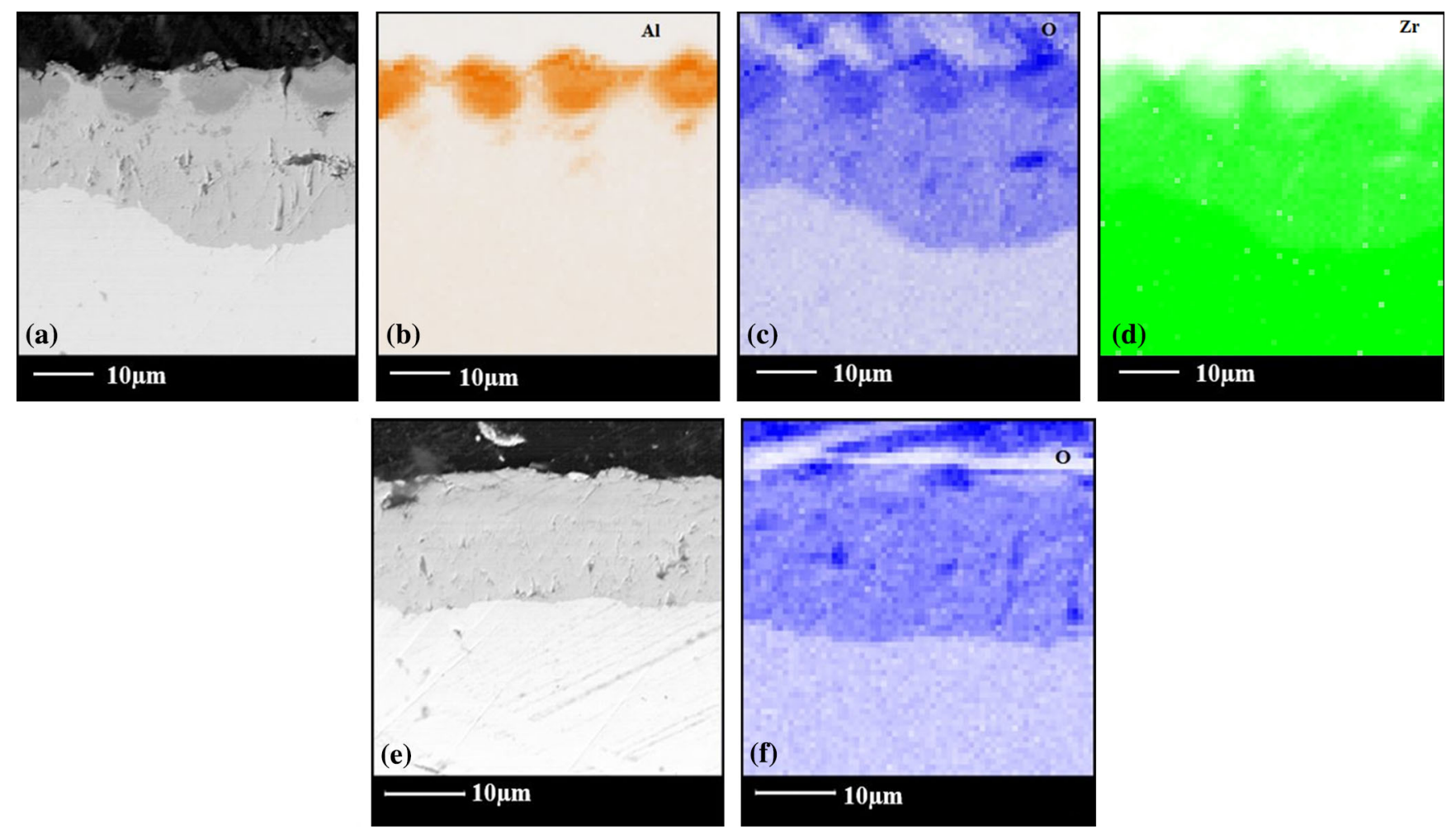

Fig. 7 Steam corrosion experiments at $1273 \mathrm{~K}$, (a) Al-doped specimen microstructure with oxide layer formation, (b) EDS mapping shows concentration of aluminum at the surface, (c) EDS mapping shows concentration of oxygen at the surface coinciding with aluminum, (d) Zirconium distribution in al-doped steam corroded specimens, (e) Pure zircaloy control specimen microstructure, (f) EDS mapping showing deeper penetration of oxygen into pure zircaloy control specimens

and migration from the bulk under layers to the specimen surface. As a general observation, in the $1273 \mathrm{~K}$ steamcorroded specimens, oxygen still seemingly penetrated into the underlying zircaloy thus not providing the anticipated protection to the fullest extent. From the micrographs and the associated elemental mapping, it was further evident that the migrating aluminum formed discontinuous clusters at the surface. This non-uniform migration and the subsequent depletion of aluminum from the under layers as seen in the EDS maps and in the doped layer is speculated to be the primary cause for oxygen reaching the underlying zirconia layer. Similar inter-diffusion behavior has been observed previously in other aluminum containing alloys such as $\mathrm{FeCrAl}$ (Ref 21).

This phenomenon is expected to be more significant at the higher test temperatures ( $\geq 1273 \mathrm{~K}$ ) as the EDS maps of the specimens tested at $1073 \mathrm{~K}$ did not indicate any significant oxidation of the underlying zirconium layer in the Al-doped specimens. This migration and formation of clusters were further evidenced by fact that at $1273 \mathrm{~K}$ the graded compositional layer, which were observed to form at the end of the heattreatment phase seemed to disappear, leading to the segregation and transport of aluminum from the underlying Al-Zr alloy. Further, qualitative observations of the corroded Al-doped specimens indicated the formation of large macroscopic defects in the form of cracks and pores on the outermost surface, which could be attributed to known phenomena such as thermal expansion, phase lattice mismatch, and complex phase transformations in the outer layers. The formation of these macroscopic defects seemingly provided easy pathways for oxygen to penetrate deep into the underlying zirconium layers. To confirm the above hypothesis, new steam corrosion experiments were performed on specimens fabricated by diffusion-bonding techniques, which had significantly higher concentrations of aluminum in the outer surfaces as compared to the sputter-coated specimens. The micrographs and the associated EDS maps of the specimen are shown in Fig. 8. It was clearly evident that increasing the concentration of aluminum was successful in completely stopping the penetration of oxygen into the underlying zircaloy even at $1273 \mathrm{~K}$.

Nevertheless, a significant observation from all these runs was the fact that the modified surface survived the hightemperature steam oxidation without noticeable evidence of large scale spalling. This was confirmed by comparing the measurements of the total thickness (using scanning electron micrographs) before and after the steam corrosion for $60 \mathrm{~min}$ in steam at the highest test temperature. Measurements revealed that the change in the total thickness of the specimens was $<5 \%$ which was qualitatively used to assess the spalling potential.

Encompassing the entire collected data on the oxide layer growth at two different temperatures in both Al-doped $(1.14 \pm 0.14 \mu \mathrm{m}$ at $1073 \mathrm{~K}$, and $27.1 \pm 1.89 \mu \mathrm{m}$ at $1273 \mathrm{~K})$ and zircaloy control $(2.17 \pm 0.15 \mu \mathrm{m}$ at $1073 \mathrm{~K}$, and $26.1 \pm 1.18$ at $1273 \mathrm{~K}$ ), and assuming the Arrhenius relationship, the $Q$ values for the pure zircaloy and Al-doped zircaloy specimens were estimated to be $141 \mathrm{~kJ} / \mathrm{mol}(\sim 1.46 \mathrm{eV})$ and $180 \mathrm{~kJ} / \mathrm{mol}(1.87 \mathrm{eV})$, respectively. The estimated $Q$ of oxygen diffusion in the control samples matched closely with the results published in the literature for the test temperature ranges 

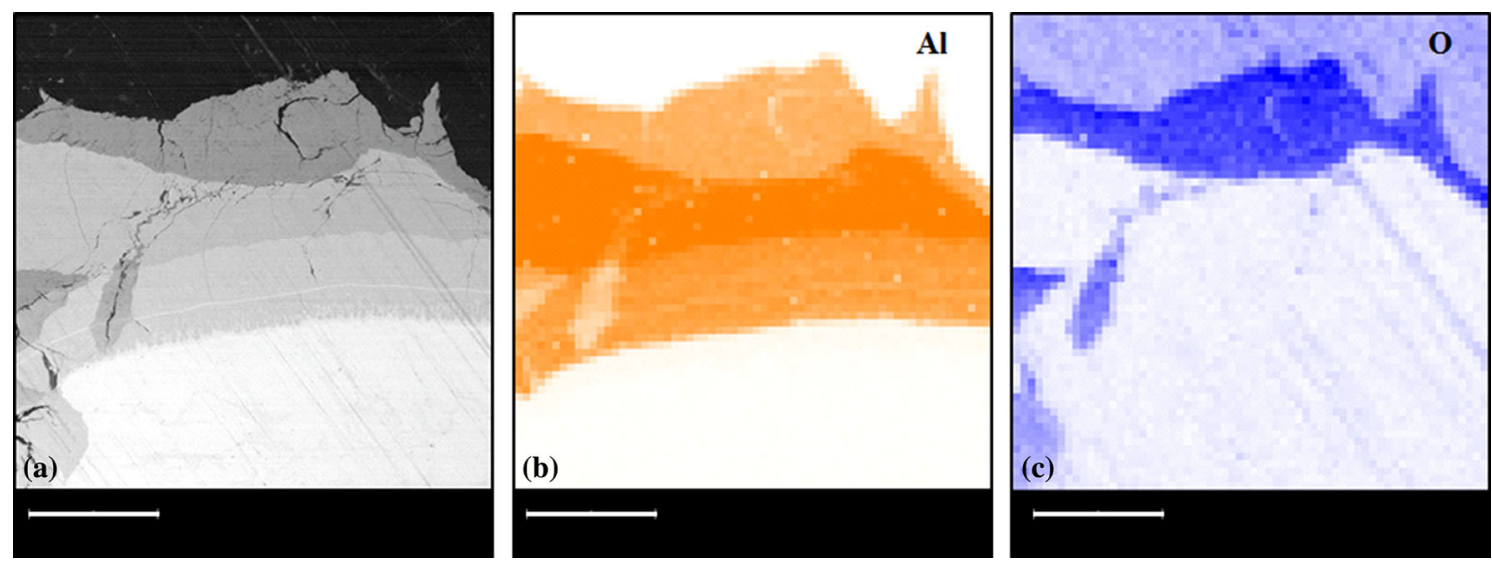

Fig. 8 Microstructure of Al-Zr diffusion layer formed using diffusion bonding technique subject to steam exposure at $1273 \mathrm{~K}$ for $120 \mathrm{~min}$

(Ref 22). The $Q$ for Al-doped zircaloy closely matched the $Q$ of aluminum diffusion in zircaloy measured during the diffusion experiments and those reported in the literature (Ref 9, 17, 19) indicating the migration of aluminum from the under layers was the rate controlling mechanism. This was also evident from the micrographs where aluminum was observed to migrate to the surface when exposed to steam, especially at $1273 \mathrm{~K}$. Investigation of the kinetics to estimate the rate constant was not attempted with existing data. It was clear that the oxidation of the under layers was more of a phenomenon precipitated by cracks in the outer alumina layers as observed in Fig. 8. The complexity of the oxidation reaction was likely controlled by the segregation and migration of aluminum in the under layers.

\subsection{Potential Impact of $\mathrm{Al}_{3} \mathrm{Zr}$ on Hydrogen Generation}

Any modification of the existing zircaloy requires a justification regarding the potential impact of the employed modification on the generation of hydrogen during a LOCA event. In this context, the following discussions are included to understand the potential effect of aluminum doping on the surface of zircaloy.

In both the diffusion and sputtering experiments, the common surface layer observed included $\mathrm{Al}_{3} \mathrm{Zr}$. As a first step to assess the potential impact of $\mathrm{Al}_{3} \mathrm{Zr}$ on the surface as opposed to pure zircaloy, a simple model was formulated (Ref 16) to theoretically compare the change in the hydrogen production rate during a high-temperature oxidation event. In current practice (Ref 16), based on the simple chemical reaction between water/steam to form $\mathrm{ZrO}_{2}$, the weight of hydrogen generated by zircaloy-steam interaction is estimated using Eq 1, where $W_{\mathrm{H} 2} \mathrm{Zr}$ represents the units of mass per unit surface area; $M_{\mathrm{H} 2}$ and $M_{\mathrm{Zr}}$ are the molecular weights of hydrogen and zirconium, respectively; $K_{\mathrm{P}-\mathrm{Zr}}$ is the parabolic rate constant; and $t$ is reaction/exposure time in seconds. Further, the parabolic rate constants for oxidation of zircaloy in high-temperature steam are estimated using Eq 2 with $R$ being the gas constant and $T$ is the test temperature.

$W_{H_{2}-\mathrm{Zr}}=\frac{2 M_{H_{2}}}{M_{\mathrm{Zr}}}\left[K_{\mathrm{p} Z \mathrm{r}} t\right]^{\frac{1}{2}}$

$K_{\mathrm{p} Z \mathrm{Zr}}=33.3 e^{\frac{-140.6}{R T}}$

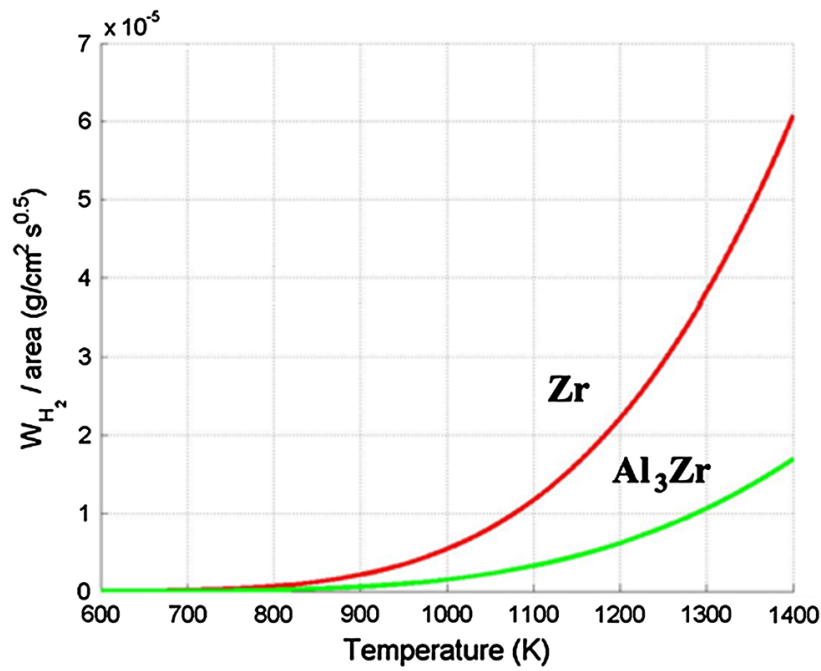

Fig. 9 Hydrogen generation model applied to pure zircaloy and Aldoped zircaloy predicting a large reduction in Al-doped zircaloy

In the present work, the model represented by Eq 1, was modified to include the effects of aluminum present in the subsurface as an alloying element for zirconium. Eq 3, a modified form of Eq 1, was employed to estimate the mass of hydrogen released per unit surface area of pure aluminum $\left(W_{\mathrm{H} 2 \_\mathrm{Al}}\right)$ assuming that every 2 moles of aluminum would generate 3 moles of $\mathrm{H}_{2}$ gas during a high-temperature oxidation event similar to the zircaloy calculations. $M_{\mathrm{Al}}$ is the molecular mass and $K_{\mathrm{p}_{\mathrm{Al}} \mathrm{l}}$ is the parabolic rate constant of aluminum under oxidation. Further, Eq 4 was employed to estimate the parabolic rate constant for $\mathrm{Al}$ as described by (Ref 23).

$W_{\mathrm{H}_{2} \_\mathrm{Al}}=\frac{3 M_{\mathrm{H}_{2}}}{2 M_{\mathrm{Al}}}\left[K_{\mathrm{p} \_\mathrm{Al}} t\right]^{\frac{1}{2}}$

$K_{p \_A l}=6.33 \times 10^{-5} e^{\frac{-138.0}{R T}}$

Based on the molar composition of $\mathrm{Al}_{3} \mathrm{Zr}$, Eq 1 and 3 can be combined as $\mathrm{Eq} 5$ where $\mathrm{W}_{\mathrm{H}_{2}}$ is the total mass of hydrogen generated per unit surface area of $\mathrm{Al}_{3} \mathrm{Zr}$. 
$W_{\mathrm{H}_{2}}=0.75 W_{\mathrm{H}_{2}-\mathrm{Al}}+0.25 W_{\mathrm{H}_{2}-\mathrm{Zr}}$

The results of the model are shown in Fig. 9. It was determined that aluminum-doped surface consisting of $\mathrm{Al}_{3} \mathrm{Zr}$ would produce approximately three time less hydrogen compared to a pure zircaloy surface. However, this model needs to be interpreted conservatively as it assumes the absence of any surface defects, which allow oxygen to penetrate to the base layer (Ref 16). Extrapolating this model to a known pressurized water reactor where at $\sim 1300 \mathrm{~K}$ a runway oxidation event of pure zircaloy cladding with a total surface area of 49 million square centimeters could potentially generate up to $100 \mathrm{~kg}$ of hydrogen in less than 20 min (Ref 16), an al-doped cladding, similar to the ones described in this work, would generate the same amount of hydrogen in $\sim 242 \mathrm{~min}$ assuming that the surface would contain sufficient quantities of aluminum at the time of the oxidation event. This increased margin is expected to provide a significant benefit in terms of reactor operator response time.

\section{Conclusions}

Attempts were made to study the behavior of self-healing aluminum-doped zircaloy surfaces in context of improving the oxidation resistance of zircaloy nuclear fuel cladding. In the first step, the diffusion of aluminum in zircaloy was studied using sandwich diffusion couples. The activation energy for aluminum transport in zircaloy was estimated to be $\sim 1.8 \mathrm{eV}$. Elemental analysis of the diffusion zones revealed the formation of two compositionally graded layers: $\mathrm{Al}_{3} \mathrm{Zr}$ and $\mathrm{Al}_{3} \mathrm{Zr}_{2}$, with the former being the predominant layer on the external surface.

To achieve better control on the purity and thickness of the diffusion zones and to reduce residual strains resulting from lattice mismatch, zircaloy specimens sputter coated with thin aluminum layers were subject to controlled heat-treatment. The microstructure of these sputtered, heat-treated specimens revealed the formation of $\mathrm{Al}_{3} \mathrm{Zr}$ surface layers similar to the diffusion specimens albeit much thinner. These specimens were subject to high-temperature steam environments at 1073 and $1273 \mathrm{~K}$ for different durations (60 and $120 \mathrm{~min}$ ). Microstructure of the steam corroded specimens indicated that the aluminum layer was intact with very little spalling. Electron micrographs of samples subject to $1073 \mathrm{~K}$ in steam for longer durations showed very little penetration of oxygen into the zirconium under layers, thus succeeding in enhancing the oxidation resistance. On the contrary, micrographs of samples subject to $1273 \mathrm{~K}$ revealed that oxygen was successful in penetrating the zircaloy under layer. This was partially attributed to two phenomena: the segregation and migration of aluminum to the surface forming discrete clusters and the formation of cracks and other defects on the surface. Analysis of steam corrosion data indicated that the migration of aluminum to the surface was perhaps the oxidation rate controlling mechanism with an estimated activation energy of $1.87 \mathrm{eV}$, which matched closely with the activation energy of aluminum transport in zircaloy. The veracity of the data was confirmed by subjecting pure zircaloy specimens to the same conditions as the Al-doped specimens and comparing the calculated activation energy values (for zircaloy) with those reported in the literature. The competing phenomenon of aluminum migration and formation of surface cracks and defects prevented further analysis of oxidation kinetics data. However, the migration of aluminum toward the surface to react with oxygen was indicative of the potential self-healing nature of this modification.

Perhaps the most significant conclusion of the experiments was the concrete evidence of aluminum in the under layers effectively diffusing to the surface, during simulated hightemperature events such as LOCA, to form mechanically stable protective layers, thus behaving like a self-healing surface. The use of aluminum in context of self-healing surfaces exhibits great potential in oxidation environments. As the experiments show, aluminum seems to effectively migrate to the surface even after forming an alloy with zirconium. To a large extent, this puts to rest the concerns of aluminum completely diffusing into the zircaloy matrix during normal operation and not contributing to increased oxidation resistance. For high temperatures, it was inferred that thicker aluminum layers would be more beneficial in increasing the oxidation resistance of the underlying zircaloy. Methods to achieve this will need to be investigated. Additional corrosion testing, including high-temperature water corrosion and neutron irradiation, will be needed to confirm the application of aluminum surface doping for applications in the nuclear industry. High-temperature high-pressure water corrosion is currently underway in pure water and 2000-ppm boric acid water to test the application of the coatings during normal operation.

\section{Acknowledgment}

The authors would like to acknowledge ATI Wah Chang for supplying the zircaloy. Support and student funding was provided by Oak Ridge National Laboratory and the Nuclear Regulatory Commission, respectively. We also would like to acknowledge the contributions of Mr. Manuel Umanzor and Mr. Yonathan Kasey to the successful completion of the experiments. In addition, the Virginia Microelectronics Center and Nanocharacterization Center at Virginia Commonwealth University also assisted with parts of this work.

\section{References}

1. D.O. Northwood, The Development and Applications of Zirconium Alloys, Mater. Des., 1985, 6, p 58-70

2. T. Alam, M.K. Khan, M. Pathak, K. Ravi, R. Singh, and S.K. Gupta, A Review on the Clad Failure Studies, Nucl. Eng. Des., 2011, 241, p 3658-3677

3. R.G. Ballinger, W.G. Dobson, and R.R. Biederman, Oxidation Reaction Kinetics of Zircaloy-4 in an Unlimited Steam Environment, J. Nucl. Mater., 1976, 62, p 213-220

4. M. Moalem and D.R. Olander, Oxidation of Zircaloy by Steam, J. Nucl. Mater, 1991, 182, p 170-194

5. K.A. Terrani, C.M. Parish, D. Shin, and B.A. Pint, Protection of Zirconium by Alumina- and Chromia-Forming Iron Alloys Under High-Temperature Steam Exposure, J. Nucl. Mater, 2013, 438, p 6471

6. G.M. Hood and R.J. Schultz, Chromium Diffusion in $\alpha$-Zirconium, Zircaloy-2 and Zr-2.5 Nb, J. Nucl. Mater., 1993, 200, p 141-143

7. W.B. Frank, W.E. Haupin, H. Vogt, M. Bruno, J. Thonstad, R.K. Dawless, H. Kvande, and O.A. Taiwo, Aluminum, Ullmann's Encyclopedia of Industrial Chemistry, Vol 76, 2000, p 598-601 
8. K.S. Forcey, D.K. Ross, and C.H. Wu, The Formation of Hydrogen Permeation Barriers on Steels by Aluminising, J. Nucl. Mater., 1991, 182, p 36-51

9. G.V. Kidson and G.D. Miller, A Study of the Interdiffusion of Aluminum and Zirconium, J. Nucl. Mater, 1964, 12, p 61-69

10. Y.S. Kim, G.L. Hofman, A.B. Robinson, J.L. Snelgrove, and N. Hanan, Oxidation of Aluminum Alloy Cladding for Research and Test Reactor Fuel, J. Nucl. Mater, 2008, 378, p 220-228

11. R. Gholizadeh Aghoyeh and H. Khalafi, Corrosion Monitoring and Determination of Aluminium Fuel Clad of Tehran Research Reactor (TRR), Prog. Nucl. Energy, 2010, 52, p 225-228

12. ASTM D3359, Standard Test Methods for Measuring Adhesion by Tape Test, 2005

13. J. Murray, A. Peruzzi, and J.P. Abriata, The Al-Zr (AluminumZirconium) System, J. Phase Equilibria, 1992, 13, p 277-291

14. H. Okamoto, Al-Zr (Aluminum-Zirconium), J. Phase Equilibria, 2002, 23, p 455-456

15. Y. Miyamoto, W. Kaysser, B. Rabin, A. Kawasaki, and R.G. Ford, Functionally Graded Materials: Design, Processing and Applications, Springer Science \& Business Media, New York, 2013
16. Nuclear Fuel Behavior in Loss-of-Coolant Accident (LOCA) Conditions, State-of-the-Art Report, Nuclear Energy Agency, Organisation for Economic Co-operation and Development, Paris, 2009

17. A. Laik, K. Bhanumurthy, and G.B. Kale, Intermetallics in the $\mathrm{Zr}-\mathrm{Al}$ Diffusion Zone, Intermetallics, 2004, 12, p 69-74

18. J. Räisänen and J. Keinonen, Diffusion of $\mathrm{Al}$ in Ion-Implanted $\alpha-\mathrm{Zr}$ and a-Hf, Appl. Phys. A, 1985, 36, p 175-178

19. J. Dickson, L. Zhou, A. Paz y Puente, M. Fu, D.D. Keiser, Jr., and Y.H. Sohn, Interdiffusion and Reaction Between $\mathrm{Zr}$ and $\mathrm{Al}$ Alloys from $425^{\circ}$ to $625{ }^{\circ} \mathrm{C}$, Intermetallics, 2014, 49 , p 154-162

20. K. Shimizu, K. Kobayashi, P. Skeldon, G.E. Thompson, and G.C. Wood, Anodic Oxidation of Zirconium Covered with a Thin Layer of Aluminium, Thin Solid Films, 1997, 295, p 156-161

21. D.J. Park, H.G. Kim, J.Y. Park, Y.I. Jung, J.H. Park, and Y.H. Koo, A Study of the Oxidation of FeCrAl Alloy in Pressurized Water and HighTemperature Steam Environment, Corros. Sci., 2015, 94, p 459-465

22. V. Urbanic and T. Heidrick, High-Temperature Oxidation of Zircaloy-2 and Zircaloy-4 in Steam, J. Nucl. Mater., 1978, 75, p 251-261

23. W. Smeltzer, Oxidation of Aluminum in the Temperature Range 400$600{ }^{\circ} \mathrm{C}$, J. Electrochem. Soc., 1956, 103, p 475 